\title{
Proses Pelepasan Mora Pada Bahasa Jepang Dalam Novel Narcissu Karya Tomo Kataoka Kajian Morfofonemik
}

\author{
Hadiid Hideo Nusantara, Nandang Rachmat, Riza Lupi Ardiati \\ Universitas Padjadjaran, Fakultas Ilmu Budaya, Jawa Barat \\ hadiidhideo8@gmail.com
}

\begin{abstract}
This article discusses the Mora disspation process in Japanese language mainly exposed by looking at the mora in literature point of view. The object that being used is a novel called "Narcissu" by the Japanese Author, Tomo Kataoka. The purpose of writing this article is to describe the disipation in Mora in Japanese language written in the form of literature. The research method used in this research is descriptive method. In analyzing the data, the author use the reference theory based on Morphology by_Iori Isao. The use of theories help the author to get to the conclusion that in Japan's daily conversation, the use of proper full mora in term of verb seldom been mention. The result of this studies show that the reason of the Mora dissipation in conversation is because of the implicitory in term of talking. In other words, it can be seen that Japanese language speaker often not using the proper word on their conversation mainly because there's a mutual understand ment in term of implicitory word that keep them talk with less word.

Keyword : Phonetic, Implicit, Mora, Morphology, Tomo Kataoka
\end{abstract}

\begin{abstract}
Abstrak
Artikel ini membahas tentang proses pelesapan Mora di dalam bahasa Jepang yang sebagian besar terlihat dari sudut pandang sastra. Objek yang digunakan berupa Novel yang berjudul "Narcisu”"oleh Penulis Jepang bernama Tomo Kataoka. Tujuan dari menulis artikel ini adalah untuk mendeskripsikan pelesapan yang terjadi di dalam bahasa Jepang yang tertulis dalam bentuk karya sastra. Metode yang digunakan dalam penelitian ini adalah metode deskriptif. Dalam menganalisis data, penulis menggunakan teori referensi berdasarkan teori morfologi oleh Iori Isao. Kegunaan dari teori tersebut bagi peneliti adalah untuk dapat membantu peneliti menarik kesimpulan bahwa penggunaan mora dalam kata kerja sangatlah jarang digunakan dalam kehidupan sehari-hari di Jepang. Hasil penelitian ini menujukkan bahwa alasan dari pelesapan Mora adalah karena keImplikasian dalam percakapan. Dengan kata lain, dapat dilihat bahwa penutur bahasa Jepang jarang menggunakan kata asli dengan menggunakan semua Mora dalam percakapan mereka karena sudah adanya pemahaman mutual dalam hal bahasa implisit yang membuat percakapan mereka lebih sedikit.
\end{abstract}

Keyword : Fonetik, Implisit, Mora, Morfologi, Tomo Kataoka

\section{PENDAHULUAN}

Ilmu Pengetahuan Bahasa dikelompokkan menjadi berbagai bidang kajian linguistik. Hal ini disebabkan agar lebih memudahkan dan memfokuskan kajian apa yang akan dipelajari. Salah satu bidang ilmu pengetahuan di dalam Linguistik adalah Morfologi. Morfologi banyak membahas tentang kata dan perubahan kata yang terjadi dalam bahasa yang digunakan. Yukawa (1994:97) mengatakan bahwa "Morfologi adalah ilmu yang mengkaji soal yang berhubungan dengan seluk-beluk kata, adanya perubahan golongan kata (fungsi gramatikal), kemungkinan perubahan makna kata akibat perubahan kata (fungsi semantik)". maka dapat dikatakan pula bahwa morfologi adalah hubungan konteks perubahan kata 
Tersedia online di http://ejournal.undip.ac.id/index.php/kiryoku

dalam kalimat dengan maksud ujaran yang disampaikan. Konteks morfologi banyak membahas tentang struktur perubahan kata dan perubahan makna yang terjadi dalam bahasa yang digunakan pada tuturan dan ujaran sehari-hari. Salah satu perubahan pada struktur kata sering mempengaruhi bunyi dari silabel maupun mora dalam pengucapan. Maka dari itu, morfologi dapat bergabung dalam penelitian perubahan katanya bersaman dengan kajian fonologi yang membahas silabel dan mora. Maka dari itu, gabungan antara kedua kajian tersebut melahirkan kajian baru bernam kajian "Morfofonemik" yang akan dibahas pada penelitian jurnal.

$$
\begin{aligned}
& \text { “音節は音の連続をいくつ かのま } \\
& \text { とまりに分けた文節的単位である } \\
& \text { が、この分け方は、モーラ（もし } \\
& \text { くは拍）と呼ばれる 単位によるも } \\
& \text { のである。”(Saito. 1997:102) }
\end{aligned}
$$

yang dapat diartikan sebagai :

'Silabel adalah satuan suku kata yang dihasilkan oleh pembagian kata berdasarkan serangkaian bunyi, tetapi cara pembagian inilah yang disebut dengan Mora.'

Dapat dilihat dalam bahasa Jepang, pembagian-pembagian serangkaian bunyi dapat mempengaruhi arti dari sebuah kata, seperti contohnya obasan dan obaasan. Kedua kata tersebut mungkin secara pengelompokan silabelnya tidaklah berbeda, tetapi lain halnya kepada Mora. Mora menghitung tiap-tiap perbedaan terkecil seperti penambahan dan pengurangan sebuah vokal dan konsonan yang ada dalam suatu kata. Dalam mora, penggunan tanda morfologi seperti /N/, /Q/, /:/ dihitung sebagai sebuah kesatuan mora yang harus dimasukkan dalam pengelompokan mora.

$$
\text { /N/ I: / I }
$$

$\begin{array}{lll}\text { 撥音 } & \text { 促音 } & \text { 長音 } \\ \mathrm{N}, \mathrm{n}, \mathrm{n} & \text { つ } & \text { aa }\end{array}$

Tetapi berbeda dengan bahasa lainnya, bahasa Jepang memiliki pengelompokan dalam kajian morfologinya. Bahasa Jepang mengelompokkan kajian morfologisnya dengan tata penulisan (文法的) dan tata pelafalannya (語彙的). Dalam bahasa Jepang, tata tulis merupakan hal yang utama dalam kehidupan sehari-hari, tetapi, tidak sepenuhnya tata tulisan yang baik dan benar diaplikasikan dalam kehidupan sehari-hari seperti halnya dalam percakapan. Sering ditemui penggunaan bahasa nonformal yang tertutur dalam percakapan bahasa Jepang. Hal ini disebabkan oleh bahasa yang digunakan merupakan salah satu bahasa yang pragmatis, di mana bahasa maupun sebuah kata yang dituturkan memiliki arti yang beragam melalui situasi maupun referensi yang telah tergambarkan sebelumnya. Hal ini dapat diteliti dengan menggunakan sebuah karya sastra sebagai data acuan penelitian.

Menurut Luxemburg (1986: 15) sering dikatakan bahwa karya sastra memang mencerminkan kenyataan, sering juga dituntut dari sastra agar mencerminkan atau merepresentasikan kenyataan. Teeuw (2003: 184) juga mengatakan bahwa Karya sastra merupakan sebuah cerminan, tiruan atau pembayangan dari realitas. Maka, dapat pula disebutkan bahwa karya sastra sebagai cerminan fenomena sosial yang terjadi karena proses pembuatannya tidak terlepas dari referensi-referensi sosial yang ditemui pengarangnya di dunia nyata dan dituangkannya dalam sebuah karya sastra.

Salah satu bentuk karya sastra adalah novel. Novel merupakan sebuah buku yang berisi kisah seseorang, baik fiksi maupun nonfiksi. Kemudian dalam representasi dunia nyatapun banyak yang tergambarkan pada karya sastra dalam bentuk novel. Craven 
(dalam Endraswara, 2011: 13) bahwa kehidupan yang tampak dalam prosa naratif (novel) merepresentasikan realitas sosial sebagai sebuah pemahaman akan kebenaran hid up untuk pembaca.

Light novel karya Tomo Kataoka yang berjudul Narcissu adalah sebuah novel ringan yang menceritakan pasien rumah sakit yaitu Yuu Atou dan Setsumi Sakura yang telah masuk ke L7 rumah sakit tersebut yang diketahui bahwa hidup mereka tidak akan lama lagi, dan jika mereka sudah mendapat kunjungan rumah untuk kedua kalinya, sudah dipastikan bahwa yang ketiga akan menjadi yang terakhir dari hidup mereka. Setsumi telah mendapat kunjungan untuk kedua kalinya, tetapi Setsumi tidakingin mengakhiri hidupnya di rumah sakit maupun di rumahnya sendiri. Walaupun begitu, yang merupakan dampak utama Setsumi mengindap depresi adalah karena ia merasa hanya menjadi beban bagi keluarganya, di mana semua harta, tenaga, dan waktu orang tuanya dikorbankan demi Setsumi seorang. Teman-teman yang dia anggap sebagai sahabat juga kian lama semakin melupakannya, dan tidak pernah lagi sekalipun datang untuk membesuk. Dengan tekanan dari luar dan perasaan dari dalam dirinya sendirinya inilah yang sangat mempengaruhi pemikiran Setsumi untuk menahan semua keinginannya dan ingin segera mengakhiri hidupnya.

$$
\begin{aligned}
& \text { 「知ってる? その時に䢽り回して } \\
& \text { た車が、その後どうなったか？」 } \\
& \text { (ナルキッソス, 2007: 200) }
\end{aligned}
$$

Shitteru? sono toki ni nori mawashite kuruma ga, sono ato dounattaka?

Tahu?/Saat itu/par/bawa/berputar/ mobilnya/par/setelah itu/bagaimana setelahnya?

"Kamu tahu nggak? Bagaimana nasib mobil yang dipakai si pasien dan temannya setelah itu?" (Narcissu, 2015: 196)

Kalimat ini merupakan dialog Yuka kepada Makie saat mereka sedang mengejar Yuu dan Setsumi sampai ke Shiga. Dalam perjalanan Yuka menceritakan kisah pasien L7 yang pernah kabur seperti Yuu dan Setsumi, yang ternyata adalah sahabat dari Yuka, yang sebenarnya membantu si pasien untuk kabur. Dia menceritakan bahwa di saat akhir hayatnya, sahabatnya memberikan mobil pelarian mereka kepada Yuka, yang mana mobil itu adalah mobil yang mereka tumpangi sekarang.

Kalimat data ini terdapat pergeseran yang terjadi yaitu pelesapan sebuah mora pada kata kerja dan juga partikel penanda kata tanya. Jika diterjemahkan secara harfiah, kalimat ini dapat diartikan menjadi 'Tahu ? mobil yang dikendarai berkeliling waktu itu, setelah itu bagaimana ?'

Dalam tata penulisan bahasa Jepang, Shitteru ini harusnya ditulis menjadi Shitteiru di mana penambahan mora /I/ menandakan makna kata berupa kejadian yang sedang dibicarakan sedang terjadi dan berkelanjutan. Tetapi dalam sebuah dialog nonformal, hal ini sering terjadi pelesapannya dikarenakan pelesapan mora ini mengurangi satu silabel atau bunyi yang dikeluarkan dalam bertutur. Dengan demikian, bahasa yang dikeluarkan lebih sedikit berbunyi, tetapi makna yang disampaikan tetaplah padat dan jelas. Dapat dikatakan pula, hal tersebut dilakukan agar memunculkan kalimat yang lebih efektif pengucapannya. Moentaha (2008:78) mengatakan bahwa "Teknik eksplikasi dalam proses penerjemahan ialah merealisasikan pengungkapan eksplisit dalam teks bahasa sasaran, karena dalam teks bahasa pemberi ada informasi yang pengungkapannya tidak jelas, yaitu ada implikasi dalam informasi tersebut (pengungkapan implisit)". 
Pemilihan objek penelitian ini didasari oleh faktor pelesapan mora akibat faktor keimplikasian sebuah bahasa yang telah di sampaikan pada konteks kalimat. Peneliti ingin memberikan khasanah yang lebih mendalam dalam penelitian linguistik morfologi yang fokus melihat cerminan percakapan sehari-hari masyarakat Jepang terhadap sudut pandang karya sastra. Ini yang menjadi daya tarik peneliti untuk melihat bagaimana fenomena pelesapan mora ini digambarkan dalam karya Sastra.

\section{LANDASAN TEORI}

Isao (2001:48) juga menyebutkan bahwa penggunaan mora atau silabel dalam sebuah kata dapat mengubah makna sebuah kata tersebut. Jika dilihat contoh seperti :

$\begin{array}{ccc}\text { 三倍 } & \text { 三台 } & \text { 三回 } \\ {[\mathrm{m}]} & {[\mathrm{y}]} & {[\mathrm{n}]} \\ \text { [sambai] } & \text { [sandai] } & \text { [sankai] }\end{array}$

Ketiga bunyi tersebut sama-sama menggunakan huruf $[ん]$ pada penggunaannya. Tetapi setelah bergabung dengan silabel lainnya, terjadi pelesapan bunyi sehingga memunculkan bunyi yang berbeda. Perubahan ini terjadi akibat satu konsonan pada sebuah silabel mengalami pelesapan terhadap konsonan setelahnya, yang mengakibatkan perubahan bunyi. Jika kita hanya melihat kepada penggalan silabelnya, maka huruf [ $\mathrm{C}$ ] tidak akan mengalami perubahan karena masih termasuk kedalam silabel /さん/san/. Tetapi jika kita melihat kepada bentukan mora, maka [ん] meru-pakan satu kesatuan yang berdiri sendiri dan dapat mengalami perubahan bunyi.

\section{METODE PENELITIAN}

Penelitian ini merupakan penelitian pustaka. Data yang digunakan berupa Data Primer, yaitu Novel Narcissu karya Tomo
Kataoka(2005) berupa penggalan kalimat yang menggunakan pelesapan mora pada setiap percakapan maupun monolog pada novel. Novel tersebut dianalisis menggunakan metode deskriptif kualitatif dengan pendekatan Linguistik Morfologi. Teknik yang digunakan dalam menganalisis adalah mencatat keterangan-keterangan melalui hasil pembacaan novel yang menunjukkan fenomena pelesapan penggalan kata agar munculnya percakapan yang implisit. Teori yang digunakan sebagai landasan dalam menganalisis adalah teori morfologi sebagai jembatan dalam pengkategorian kata dalam struktur kalimat agar dapat mengkaji lebih lanjut akan terjadinya penghilangan atau pelesapan yang terjadi pada bahasa Jepang dengan hasil dari terjemahan bahasa Ind onesia.

\section{PEMBAHASAN}

Pada penelitian ini, peneliti menemukan 14 data pada novel acuan yang digunakan. Tetapi peneliti hanya akan memasukkan tiga data penelitian karena ketiga data sudah mewakili semua data yang akan diteliti nantinya.

Contoh 1 :

$$
\begin{aligned}
& \text { 秋を迎ええ、冬へ越し、入院、 } \\
& \text { 退院、通院....... そしてまた入院繰 } \\
& \text { り返し ....... } \\
& \text { (ナルキッソス, 2007: 13) }
\end{aligned}
$$

Aki wo mukae, fuyu wo koshi, nyuuin, taiin. Tsuuin...... soshite mata nyuuin wo kurikaeshi.....

Musim gugur/par/ menjemput/musim dingin/ par/ melewati/ berganti rumah sakit/ lalu/ lagi/ masuk rumah sakit/ par/ mengulang

Menjelang musim gugur, selepas musim dingin -masuk RS, keluar RS, rawat jalan... 
( Narcissu, $2015: 8$ )

Kalimat ini merupakan monolog Setsumi pada pembukaan cerita (Prolog) saat dia menceritakan masa lalunya yang sering keluar-masuk rumah sakit karena penyakit yang memang sudah lama dia derita dan semakin lama semakin bertambah buruk.

Kalimat data ini terdapat pergeseran yang terjadi yaitu pelesapan sebuah mora pada kata kerja pada kata sambung pembentuk kalimat majemuk. Jika diterjemahkan secara harfiah, kalimat ini dapat diartikan menjadi 'menghadapi musim gugur, melewati musim dingin, masuk rumah sakit, keluar rumah sakit, lanjut masuk rumah sakit...... lalu lanjut mengulang masuk rumah sakit'.

Dalam tata penulisan bahasa Jepang, mukae ini harusnya ditulis menjadi mukaete di mana penambahan mora /te/ menandakan makna kata berupa kejadian yang sedang dibicarakan telah terjadi sebelumnya dan berlanjut kepada situasi selanjutnya. Dalam bahasa Jepang, penggunaan kat verba berkelanjutan dan menyambungkan kalimat selanjutnya agar dapat menjadi satu kalimat majemuk dapat menggunakan perubahan morfologi て形. Sama halnya dengan koshi, koshi seharusnya memiliki tambahan mora /te/ pada bagian akhir katanya. Tetapi dalam sebuah dialog nonformal, hal ini sering terjadi pelesapannya dikarenakan pelesapan mora ini mengurangi satu silabel atau bunyi yang dikeluarkan dalam bertutur. Dengan demikian, bahasa yang dikeluarkan lebih sedikit berbunyi, tetapi makna yang disampaikan tetaplah padat dan jelas. Dapat dikatakan pula, hal tersebut dilakukan agar memunculkan kalimat yang lebih efektif pengucapannya.

Contoh 2:

$$
\begin{aligned}
& \lceil\ldots . . . \text { そう見える?」 } \\
& \text { (ナルキッソス, 2007: 67) }
\end{aligned}
$$

\section{......Sou mieru? \\ Seperti itu/ kelihatannya \\ "...Memangnya terlihat menarik bagimu?“}

( Narcissu, $2015: 63$ )

Kalimat ini merupakan dialog Setsumi kepada Yuu saat Yuu melihat dirinya sedang menatap dirinya sedang memandangi televisi yang menayangkan tayangan yang menjemukan. Yuu yang sudah memantapkan dirinya untuk kabur dari $R S$ menyapa Setsumi untuk menarik perhatiannya yang terlihat seperti melambung jauh dalam kehampan.

Kalimat data ini terdapat pergeseran yang terjadi yaitu pelesapan sebuah mora pada partikel penanda kata tanya. Jika diterjemahkan secara harfiah, kalimat ini dapat diartikan menjadi 'Terlihat seperti itu ?'

Dalam tata penulisan bahasa Jepang, mieru ini harusnya ditulis menjadi mieruka di mana penambahan mora $/ \mathrm{ka} /$ menandakan makna kata berupa si penutur sedang melontarkan sebuah pertanyaaan kepada lawan bicara, bukan melontarkan sebuah pernyataan. Tetapi dalam sebuah dialog nonformal, hal ini sering terjadi pelesapannya dikarenakan pelesapan mora ini mengurangi satu silabel atau bunyi yang dikeluarkan dalam bertutur. Dengan demikian, bahasa yang dikeluarkan lebih sedikit berbunyi, tetapi makna yang disampaikan tetaplah padat dan jelas. Dapat dikatakan pula, hal tersebut dilakukan agar memunculkan kalimat yang lebih efektif pengucapannya.

Contoh 3 :

「ほら、ガソリン代くらいなら、 金も足りるかも知れないし」(ナ ルキッソス, 2007: 100)

Hora, Gasorindai kurainara, kane mo tariru kamoshirenaishi 
Hei/ uang gasolin/ kalau cuma/ uang/ juga/ cukup/ mungkin

"Begini, uang kita mungkin cukup untuk membayar ongkos bahan bakar ke sana kalau kita Pakai jalan biasa." (Narcissu, 2015 : 97)

Kalimat ini merupakan dialog Yuu kepada Setsumi saat mereka sedang melaju tanpa arah tujuan dengan mobil ayah Yuu yang mereka "pinjam". Dalam perjalanan Yuu kebingungan dengan arah jalan menuju pulau Awaji. Pulau Awaji (淡路島 Awajishima) adalah nama sebuah pulau di Jepang yang terletak bagian timur Laut Pedalaman Seto. Pulau ini berada di wilayah Kinki dan merupakan wilayah Prefektur Hyogo. Bekas wilayah Provinsi Awaji pada masa pembagian provinsi lama (wikipedia.com).

Berbeda dengan contoh kalimat sebelumnya, kalimat data ini terdapat pergeseran yang terjadi yaitu kemunculan sebuah mora yang seharusnya dapt dilesapkan pada perubahan morfologi kata kerja. Jika diterjemahkan secara harfiah, kalimat ini dapat diartikan menjadi 'Hei, jika harga bahan bakar, mungkin uang cukup dan'

Dalam tata penulisan bahasa Jepang, kamoshirenaishi ini harusnya ditulis menjadi kamoshirenai saja, dimana penambahan mora /shi/ menandakan makna kata berupa kejadian yang sedang dibicarakan sedang terjadi dan memiliki kelanjutan pada kalimat selanjutnya, yang menandakan bahwa kalimat ini adalah kalimat majemuk. Tetapi setelah dilihat kembali, kalimat ini tidak ada kelanjutan dari pernyataan sebelumnya, sehingga hanya menambahkan makna berkelanjutan tanpa adanya kelanjutan nyata yang tersuratkan. Tetapi dalam sebuah dialog nonformal, hal ini sering terjadi penambahannya dikarenakan si penutur sebenarnya menunggu respon dari lawan bicara. mora ini menambahkan satu silabel atau bunyi yang dikeluarkan dalam bertutur. Dengan demikian, bahasa yang dikeluarkan lebih mengharapkan sebuah respon dengan memotong kalimat tunggal yang sebenarnya tidak ada, tetapi makna yang disampaikan tetaplah padat dan jelas. Dapat dikatakn pula, hal tersebut dilakukan agar memunculkan kalimat yang lebih relevan dan efektif pengucapannya.

\section{Relevansi Isi Novel dengan Fakta Sosial}

Dalam percakapan sehari-hari Jepang, terlihat bahwa hal ini benar ad anya. Pelesapan mora dalam bahasa percakapan sering terjadi di dalam bahasa Jepang. Sebagai contoh, saat orang sedang mengungkap apakah lawan bicara dapat memakan sesuatu dihadapannya

「食べれるか。」(taberuka?). Lawan bicara akan menjawab 'iya' atau 'tidak'. Di sini terlihat bahwa pengunaan kata ini sama artinya dengan tata penulisan「食べられる か。」di mana berarti kata 'makan' yang mengalami perubahan morfologi bentuk 可能 形 (Kanoukei) atau bentuk 'dapat' atau bentuk 'potensial'. Kedua kalimat pendek di atas sama-sama memiliki makna yang sama, yaitu 'Apakah (lawan bicara) dapat memakan (makanan yang ditujukan) ?'. Lawan bicara dapat memahami apa maksud dari penutur kalimat karena bahasa dan perkataan yang diucapkan merupakan sebuah keimplisitan dari makna kata yang sebenarnya.

\section{SIMPULAN}

Penggunaan pelesapan mora pada kalimat pecakapan sehari-hari bahasa Jepang memang sering diguanakan. Hal ini dikarenakan penggunaan bahasa yang implisit yang sering digunakan oleh orang Jepang dalam menyampaikan maksud dari konteksnya. Mereka dapat memahami isi konteks pemmbicaraan dengan makna yang disampaikan melalui sisi kesingkatan dan 
Kiryoku: Jurnal Studi Kejepangan, Volume 5 No 12021

e-ISSN:2581-0960 p-ISSN : 2599-0497

Tersedia online di http://ejournal.undip.ac.id/index.php/kiryoku

kepadatan kata. Dengan demikian, mereka tidak perlu menggunakan bahasa yang eksplisit, tetapi dapat menggunakan bahasa yang lebih singkat, padat, dan jelas.

\section{DAFTAR PUSTAKA}

Alwi, Hasan, Dkk. 2010. Tata Bahasa Baku Bahasa Indonesia. Jakarta: Balai Pustaka.

Depdikbud. 1996. Kamus Besar Bahasa Indonesia. Jakarta : Balai Pustaka.

Hideo Nusantara, Hadiid. 2018. Teknik Eksplikasi dan Implikasi Terjemahan ke Dalam Bahasa Indonesia pada Novel Narcissu Karya Kataoka Tomo : Kajian Eksplikasi dan Implikasi. Tidak diterbitkan. Universitas Padjadjaran

Iori, Isao. 2000. Nihongo Bunpou Handobukku. Tokyo: Surii E Nettowaaku. Iori, Isao. 2001. Atarashii Nihongogaku Nyuumon. Tokyo: 3A Corporation

Kataoka, Tomo. 2008. Narcissu. Tokyo : Kadokawa Corporation

Kataoka, Tomo. 2015. Narcissu. Terjemahan oleh Denis Agung. Jakarta : PT Eaststar Adhi Citra

Kridalaksana, Harimurti. 1992. Pembentukan Kata dalam Bahasa Indonesia. Jakarta : PT Gramedia Pustaka Utama

Moentaha, Salihen. 2006. Bahasa dan Terjemahan. Bekasi : Kesaint Blanc.

Sudjianto dan Ahmad Dahidi. 2012. Pengantar Linguistik Bahasa Jepang. Jakarta: Kesaint Blanc Publishing

Sutedi, Dedi. 2008. Dasar-dasar Linguistik Bahasa Jepang. Bandung: Humoniora

Tomita, Takayuki. 2015 Bunpo no kiso chishiki to sono oshiekata Tokyo : Bonjinsha

Tanaka, Harumi. 1982 Gengogaku Enshuu. Tokyo: Taishukan Shoten.

Saito, Yoshio. 1997. Nihongo Onseigaku Nyuumon. Tokyo: Sanseido.co
Yukawa, Yasutoshi. 1994, Gengokaku. Tokyo: Hosou Daigaku Kyouzai 